\title{
PEMANFAATAN JEJARING SOSIAL TWITTER SEBAGAI MEDIA PENYEBARAN INFORMASI PUBLIK (Studi Pada Akun Twitter@djplkemenhub151)
}

\author{
Rahayu Amanda \\ Program Studi IImu Komunikasi FIS Universitas Negeri Jakarta \\ Email: rahayuamanda295@gmail.com
}

\begin{abstract}
ABSTRAK
Direktorat Jenderal Perhubungan Laut (DJPL) memiliki media sosial twitter untuk menyebarkan informasi publikdengan nama pengguna@djplkemenhub151. Tujuan dari penelitian ini adalah untuk mengetahui bagaimana pemanfaatan jejaring sosial twitter sebagai media penyebaran informasi publik oleh Humas DJPL. Teori yang digunakan pada penelitian ini adalah The Circular Model of SoMe, terdiri dari 4 tahap yaitu Share (berbagi), Optimize (optimisasi), Manage (mengelola), dan Engage (melibatkan) yang dikemukakan oleh Regina Luttrell. Keempat tahapan model komunikasi di media sosial tersebut digunakan untuk mengetahui apakah pemanfaatan jejaring sosial twitter sebagai media penyebaran informasi publik oleh Humas DJPL sudah berjalan secara optimal atau belum. Penelitian ini menggunakan metode penelitian etnometodologi. Teknik pengumpulan data yang digunakan dalam penelitian ini adalah wawancara mendalam dan studi kepustakaan. Wawancara mendalam dilakukan dengan satu orang key informan dan dua orang informan. Penelitian ini menggunakan triangulasi sumber karena membandingkan data atau informasi melalui wawancara. Hasil penelitian menunjukan pada tahap share, media sosial twitter yang dipilih Humas DJPL sudah tepat. Pada tahap optimize, pemanfaatan twitter DJPL belum dilakukan secara maksimal karena Humas DJPL tidak memiliki strategi khusus dalam mengembangkan akun twitternya. Pada tahap manage, Humas DJPL melakukan media monitoring secara manual dan terdapat kendala keterbatasan Sumber Daya Manusia (SDM) sehingga pengelolaan twitter DJPL masih sama dengan media sosial DJPL lain, artinya tidak memiliki admin pengelola khusus. Pada tahap engage, Humas DJPL belum menggunakan influencer pada akun media sosial twitternya dan belum memiliki cara efektif untuk menarik minat followers melakukan interaksi pada akun twitter@djplkemenhub151.
\end{abstract}

Kata Kunci: Direktorat Jenderal Perhubungan Laut (DJPL), Twitter, The Circular Model of SoMe

\section{PENDAHULUAN}

Di era digital ini, internet memiliki peran yang sangat besar dalam penyebaran informasi publik. Kehadiran internet membuat arus informasi semakin mudah dan cepat. Internet menjadi media yang paling banyak digunakan untuk memenuhi kebutuhan akan informasi serta menunjang aktivitas. Perkembangan internet di Indonesia mengalami peningkatan secara signifikan setiap tahunnya. Hal ini berdasarkan data dari Kementerian Komunikasi dan Informatika RI 
pada tahun 2020 pengguna internet di Indonesia tercatat mencapai sekitar 175, 5 juta jiwa dari jumlah populasi sebanyak 268.583.016 penduduk. Terdapat kenaikan sebanyak 25 juta atau 17 persen dibandingkan dengan tahun sebelumnya pada 2019 (Kominfo: Pengguna Internet Di Indonesia Capai 175,5 Juta | Republika Online, n.d.).

Salah satu fasilitas internet yang sering digunakan dalam penyebaran informasi publik secara luas adalah media sosial. Penyebaran informasi melalui media sosial merupakan salah satu bentuk modernisasi praktisi humas dalam menyampaikan informasi kepada publiknya. Informasi yang disampaikan oleh seorang praktisi humas harus informatif dan dikemas dengan baik agar menarik minat masyarakat untuk memberikan respon pada konten-konten yang diposting sehingga dapat meningkatkan terjadinya interaksi pada media sosial tersebut.

Twitter merupakan sebuah layanan microblogging yang sangat efektif untuk menjadi wadah dalam menjalin hubungan pertemanan dengan setiap orang yang ada di belahan dunia untuk dapat berkomunikasi, melakukan pertukaran informasi berupa foto, video ataupun tulisan dengan kecepatan sepadan dengan media masa konvensional (Tomasoa et al., 2019). Kini semakin banyak pengguna twitter karena media sosial tersebut menawarkan berbagai kemudahan seperti dapat menyambungkan secara langsung dengan laman website atau tautan berita, dapat mencantumkan tautan video dengan durasi sepanjang 40 detik sebagai bentuk komunikasi visual, dapat mencantumkan gambar atau infografis, memungkinkan komunikasi dua arah melalui fitur comment, retweet dan likes, serta dapat memperkuat ikatan antara berbagai pengguna dan mendukung interaktivitas melalui fitur mention dan hashtag (Puspitaningrum \& Laura, 2020).

Menurut hasil survey yang dikeluarkan oleh WeAreSocial dan Hootsuite pada Januari 2021, Indonesia merupakan negara dengan pengguna media sosial twitter terbesar peringkat keenam di dunia seperti berita yang dikutip dari DataReportal.com di bawah ini:

"They were 170.0 million social media users in Indonesia in January 2021. The number of social media users in Indonesia increased by 10 million ( $+6.3 \%$ ) between 2020 and 2021. The number of social media users in Indonesia was equivalent to $61.8 \%$ of the total population in January 2021."

\section{Gambar 1 Data Pengguna Media Sosial di Indonesia tahun 2021 (Sumber: DataReportal.com)}




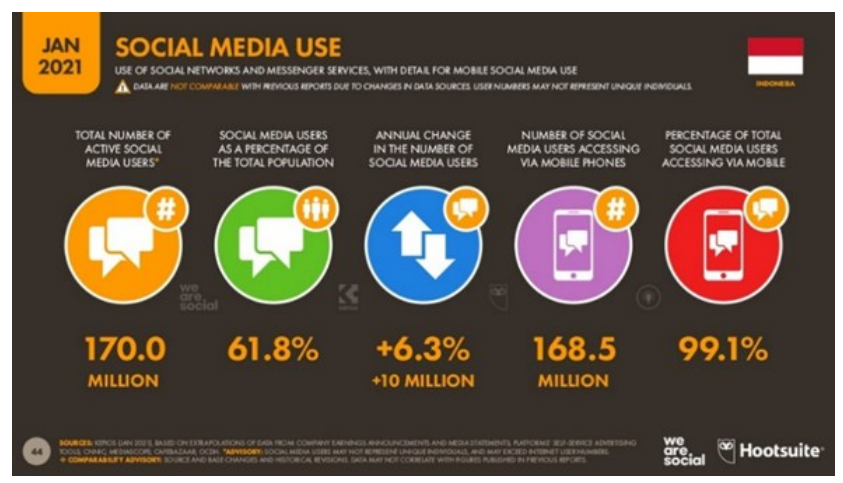

Saat ini hampir semua lembaga atau instansi pemerintahan menggunakan twitter sebagai media penyebaran informasi publik, salah satunya adalah Direktorat Jenderal Perhubungan Laut Kementerian Perhubungan RI. Dengan nama pengguna twitter (a)djplkemenhub151, akun tersebut pertama kali dibuat pada tahun 2016. Akun twitter DJPL memiliki follower sebanyak 4.643 dengan tweets berjumlah 10.600. Adapun Khrisna Dwi Nugraha selaku Staf Penyusun Bahan Publikasi dan Kehumasan DJPL menuturkan bahwa alasan penggunaan twitter DJPL sebagai media penyebaran informasi publik karena twitter menjadi platform media sosial yang dapat memberi kemudahan pada pengguna serta dalam penyebaran informasi secara luas hanya memerlukan waktu yang singkat.

Dalam pengelolaan media sosial twitter DJPL masih terdapat kendala. Sesuai dengan pernyataan key informan dengan nama Khrisna Dwi Nugraha yang menjelaskan bahwa kendala berupa keterbatasan Sumber Daya Manusia (SDM) sehingga pengelolaan twitter DJPL masih dilakukan oleh satu orang admin dimana admin tersebut mengelola seluruh media sosial DJPL. Seperti dikatakan oleh Mustika Desi Rahmadhan yang merupakan follower@twitter@djplkemenhub151 menuturkan bahwa komentarnya tidak pernah mendapatkan feedback dari admin twitter DJPL dan pada akun twitter DJPL masih jarang sekali terjadi interaksi.

Akun twitter resmi DJPL aktif dan rutin membagikan informasi publik. Namun, tingkat engagementnya masih rendah karena kurangnya interaksi antara follower dengan admin twitter DJPL. Walaupun twitter DJPL memiliki 4.643 followers, tetapi interaksi yang dilakukan instansi dan feedback dari follower tersebut sangat jarang terjadi. Permasalahan ini dapat dilihat dari komentar follower pada postingan konten akun twitter @djplkemenhub151, dimana komentarkomentar tersebut tidak pernah mendapat feedback dari admin twitter DJPL.

Humas DJPL dalam mengelola media sosial twitter dan menyebarkan informasi publik tentu memiliki strategi. Strategi tersebut harus dapat meningkatkan interaktivitas pada akun twitter@djplkemenhub151 sehingga pemanfaatan twitter sebagai media penyebaran 
informasi publik dapat berjalan secara lebih optimal. Oleh karena itu, permasalahan penelitian ini berjudul "Pemanfaatan Jejaring Sosial Twitter Sebagai Media Penyebaran Informasi Publik (Studi Deskriptif Kualitatif Pada AkunTwitter@djplkemenhub151)”.

\section{TINJAUAN PUSTAKA}

\section{The Circular Model of SoMe (Model Sirkuler Media Sosial)}

Luttrell memaparkan suatu model komunikasi melalui media sosial yang dilakukan oleh Public Relations. Model tersebut disebut Circular Model of SoMe for Social Communications: Share, Optimize, Manage, Engage. Luttrell menjelaskan bahwa model ini belum diterima secara luas, namun walaupun begitu model ini berlandasakan dukungan fundamental Cluetrain Manifesto dan model komunikasi dua arah simetris Grunig (Luttrel, 2019).

a. Share (berbagi)

Luttrell menekankan ada 3 hal yang harus diperhatikan di tahap Share (membagikan), yaitu participate, connect, dan build trust (Luttrel, 2019). Artinya, dalam melakukan upaya membagikan suatu pesan atau informasi, subjek harus berpartisipasi dalam media sosial itu sendiri. Jadi, perusahaan diharuskan untuk melakukan aktivitas media sosial yang akan digunakan.
Media sosial yang digunakan sebaiknya memiliki unsur share agar bisa saling menghubungkan publik di media sosial tersebut baik dengan atau tidak dengan peran subjek itu sendiri. Karena dengan demikian apabila publik sudah berinisiasi membagikan suatu pesan tertentu berkenaan tentang subjek, tidak hanya jaringan cakupan informasi saja yang meluas, tapi juga akan terbangun kepercayaan pada publik.

\section{b. Optimize (optimisasi)}

Dalam tahap optimize ini ada dua poin yang harus di perhatikan. Pertama adalah listen \& learn, bagaimana subjek dapat mendengarkan dan memahami apa yang sedang di perbincangkan oleh publik terhadap subjeknya. Kedua adalah take part in authentic communications, bagaimana subjek melibatkan diri dalam suatu percakapan yang dilakukan oleh publiknya. Listen and Learn yaitu melakukan pengecekan tagar dan mention secara manual dan informasi juga didapat melalui laporan langsung dari khalayak. Take part in authentic conversation yaitu menggunakan narasi positif dan humanis, menggunakan fungsi hastag untuk terlibat dengan audien (Luttrel, 2019).

c. Manage (mengelola)

Menurut Luttrel (2019) dalam tahap manage (mengelola), ada tiga yang perlu 
diperhatikan dalam melakukan kegiatannya di media sosial. Pertama, bagaimana subjek melakukan media monitoring, bagaimana subjek memberikan respon yang cepat (quick responses), dan yang terakhir bagaimana subjek melakukan interaksi dalam waktu yang sebenar-benarnya (real-time interaction). Media monitoring yaitu memeriksa semua pemberitaan dan dievaluasi, memeriksa pertumbuhan follower dan like secara manual. Quick Response meliputi mengutamakan respon pada komentar dan adanya komentar masyarakat yang tidak dibalas dikarenakan kurangnya data.

\section{d. Engage (melibatkan)}

Lutrell mengatakan ada tiga hal yang harus diperhatikan pada tahapan engage. Hal pertama adalah influencer relations, yang membahas bagaimana subjek menjalin relasi dengan para influencernya (pihak yang dipandang dan dapat memberi pengaruh). Hal kedua adalah knowing the audience, yang membahas bagaimana subjek mengetahui dan memahami segala seluk beluk tentang target audiennya. Hal ketiga adalah Reach. Reach membahas bagaimana subjek meraih target audien nya dan dengan cara seperti apa meraihnya. Influencer Relations yaitu menjalin kerja sama dengan influencer dan memenuhi hak dan kewajiban dengan influencer.
Knowing the audiences yaitu melakukan riset terhadap target khalayak dengan cara mengamati melalui akun media sosial yang banyak diikuti oleh target khalayak (Luttrel, 2019).

\section{Media Baru}

Media baru merupakan istilah yang dipakai untuk semua bentuk media komunikasi massa yang berbasis teknologi informasi. Media baru yang memiliki ciri tersebut adalah internet. Internet adalah jaringan kabel dan telepon satelit yang menghubungkan komputer. Media baru merupakan sebuah sebutan untuk menjelaskan konvergensi antara teknologi komunikasi digital yang terkomputerisasi serta hubungan ke dalam jaringan.

Ciri media baru internet menurut Denis Mc Quil pertama, internet tidak hanya berkaitan dengan produksi dan distribusi pesan, tetapi juga dapat disertakan dengan pengolahan, pertukaran dan penyimpanan. Kedua, media baru merupakan lembaga komunikasi publik dan privat, dan diatur (atau tidak) dengan layak. Ketiga, mereka tidak seteratur bagaimana media massa yang profesional dan birokratis. Terdapat perbedaan signifikan yang menekankan fakta bahwa hubungan media baru dengan media massa adalah pada penyebarannya yang luas, secara 
prinsip tersedia untuk semua jenis komunikasi, dan setidaknya bebas dari kontrol, bila sebelumnya masyarakat mengenal media konvensional (media cetak, radio, televisi, film), kini telah diperkenalkan media baru (internet) (Syaban et al., 2018).

Media sosial adalah sebuah media online dimana para penggunanya dapat dengan mudah berpartisipasi, berbagi dan menciptakan isi meliputi blog, sosial network atau jejaring sosial, wiki, forum dan dunia virtual lainnya. Blog, jejaring sosial dan wiki mungkin merupakan bentuk media sosial yang paling umum digunakan oleh masyarakat diseluruh dunia (Cahyono, 2016).

Media sosial memiliki banyak bentuk, diantaranya yang paling popular adalah microblogging (twitter), facebook dan blog. Twitter merupakan media sosial yang hadir dengan format yang berbeda, dimana twitter memiliki konsep yaitu menyebarkan informasi pesan secara singkat, padat dan real time dengan kalimat yang kurang dari 140 karakter kepada pembacanya di seluruh dunia yang bisa digunakan sebagai sarana penyebar informasi kepada semua orang baik yang dikenal maupun tidak, untuk memberitahukan keberadaan penggunanya (Puspitadewi et al., 2016).

\section{Informasi Publik}

Informasi publik dalam Pasal 1 angka (2) UU No. 14/2008 adalah informasi yang dihasilkan, disimpan, dikelola, dikirim, dan atau diterima suatu badan publik yang berkaitan dengan penyelenggara dan penyelenggaraan badan publik lainnya sesuai dengan UU. Adapun informasi yang wajib diumumkan secara berkala berdasarkan UU KIP dalah meliputi:

a. Informasi yang berkaitan dengan Badan Publik;

b. Informasi mengenai kegiatan dan kinerja Badan Publik terkait;

c. Informasi mengenai laporan keuangan; dan/atau

d. Informasi lain yang diatur dalam peraturan perundang-undangan (Herdiana, 2017)

\section{METODE PENELITIAN}

Pendekatan yang digunakan dalam penelitian ini adalah pendekatan kualitatif. Pada penelitian ini peneliti menggunakan metode etnometodologi. Teknik pengumpulan data yang digunakan adalah wawancara mendalam dan studi kepustakaan. Wawancara mendalam dilakukan dengan satu orang key informan dan dua orang informan terpilih. Penelitian ini menggunakan teknik analisis data melalui model analisis data interaktif dari Miles dan Huberman. Dalam menganalisis data hasil penelitian, peneliti menggunakan 
langkah-langkah antara lain:

1. Pengumpulan Data (Data Collection)

Peneliti mendalami sosial atau objek yang diteliti. Semua data yang didapatkan melalui penglihatan atau suatu hal yang dapat didengar, direkam agar data yang didapatkan lebih bervariasi, akurat dan hasil wawancara yang didapatkan sangat banyak.

2. Reduksi Data (Data Reduction) Ketika data yang didapat dari lapangan jumlahnya sudah cukup banyak, maka peneliti perlu mencatat dan menyaring secara teliti dan rinci. Mereduksi data merangkum atau memilih hal-hal yang penting (Sugiyono, 2017).

3. Penyajian Data (Data Display) Penyajian data yang peneliti lakukan dalam bentuk uraian singkat flowchart, dan sejenisnya. Dengan mendisplaikan data, akan memudahkan untuk memahami apa yang terjadi, merencanakan kerja selanjutnya berdasarkan apa yang telah dipahami tersebut.

4. Penarikan Kesimpulan (Verification)

Peneliti menarik kesimpulan dari data yang telah didapatkan. Hasil awal pada data yang didapatkan itu masih bersifat sementara, dan masih dapat berubah ketika munculnya banyak bukti yang mendukung data tersebut (Sugiyono, 2017).

\section{HASIL DAN PEMBAHASAN PENELITIAN}

\section{Media Sosial Twitter DJPL}

Direktorat Jenderal Perhubungan Laut menggunakan berbagai media sosial untuk penyebaran informasi antara lain Facebook, Twitter, Instagram, Tiktok, Youtube. Pada penelitian ini peneliti sangat tertarik untuk meneliti salah satu media sosial milik DJPL, yaitu twitter.

Key informan yang menyebutkan bahwa penggunaan twitter itu sangat penting apalagi di era 4.0 saat ini karena menjadi salah satu media untuk publikasi kepada masyarakat,

"Direktorat Jenderal Perhubungan Laut DJPL merupakan instansi atau lembaga pemerintahan yang membidangi perhubungan laut di Indonesia. DJPL memiliki 5 media sosial yaitu Facebook, Twitter, Instagram, Tiktok, dan Youtube. Seluruh media sosial DJPL dikelola oleh satu orang admin yang bertugas mempublikasikan konten dan menjalankan lalu lintas komunikasi di media sosial. Penggunaan media sosial twitter itu sangat penting ya. Apalagi di era 4.0 seperti saat ini karena menjadi media untuk publikasi kepada masyarakat." (Wawancara dengan key informan Krishna Dwi Nugraha, Selasa, 15 Juni 2021 Pukul 07.45 WIB)

Direktorat Jenderal Perhubungan Laut (DJPL) menggunakan twitter sebagai media 
penyebaran informasi publik seperti informasi mengenai kebijakan perhubungan laut, kegiatan-kegiatan DJPL, hingga pencapaian DJPL. DJPL ingin menjangkau lebih banyak audien melalui platform media sosial twitter, karena twitter memberi kemudahan melalui fitur-fitur yang tersedia seperti tweet, reply, retweet, like, message, share dan hashtag.

\section{Gambar 2 Twitter Engagement @djplkemenhub151 (Sumber: app.brand24.com)}

\section{\ Summary}

$\begin{array}{lllll}\text { MENTIONS } & \text { SM REACH } & \text { INTERACTIONS } & \text { POSITIVE } & \text { NEGATIVE } \\ 110 & 145 \mathrm{~K} & 390 & 32 & 12 \\ +109(+10900 \%) & +145 \mathrm{~K}(+100 \%) & +390(+100 \%) & +32(+100 \%) & +12(+100 \%)\end{array}$

Menurut Kapoor (2011) engagement dianggap sebagai sinonim untuk komitmen dan kewajiban, engagement tampaknya memiliki konotasi positif, mengekspresikan kesenangan dan kegembiraan, bukan hanya melakukan tugas atau dedikasi. (Kapoor, 2011) Pernyataan ahli tersebut sesuai dengan pernyataan key informan dengan nama Khrisna Dwi Nugraha yang mengatakan bahwa engagement antara follower dan instansi itu penting,

"Engagement itu sangat penting untuk mengetahui konten seperti apa yang disukai publik dan konten seperti apa yang mendapat respon sedikit dari follower, sehingga dapat menjadi bahan untuk evaluasi kita." (Wawancara dengan key informan Krishna Dwi Nugraha, Selasa, 15 Juni 2021 Pukul 07.45 WIB)

Berdasarkan data yang peneliti dapatkan dari app.brand24.com, tingkat engagement dari twitter@djplkemenhub151 masih rendah. Hal ini dikarenakan kurangnya interaksi antara admin twitter dan follower twitter DJPL. Untuk meningkatkan interaktivitas pada akun twitter DJPL dibutuhkan sebuah strategi, nantinya strategi ini diharapkan dapat lebih mengoptimalkan pemanfaatan media sosial twitter sebagai media penyebaran informasi publik.

\section{Interaktivitas Pada Akun Twitter @djplkemenhub151}

Pada pengelolaan media sosial twitter DJPL, interaksi dengan follower sangat diperlukan untuk menciptakan hubungan yang baik dan untuk mengetahui keefektifan dari penyebaran informasi yang dilakukan oleh Humas DJPL melalui media sosial twitter. Selain itu, interaksi yang dilakukan oleh 
follower dan admin twitter akan berpengaruh terhadap meningkatnya engagement twitter.

Diketahui pada postingan konten twitter @djplkemenhub151, follower dan instansi jarang terlibat interaksi satu sama lain. Hal tersebut sesuai dengan yang disampaikan oleh key informan dengan nama Khrisna Dwi Nugraha bahwa admin twitter DJPL tidak terlalu aktif menanggapi respon dari follower twitter DJPL,

"Tidak terlalu aktif karena adminnya kan mengelola seluruh media sosial DJPL sehingga tidak terlalu memerhatikan respon yang masuk dari follower twitter, terkadang sekedar melihat saja namun tidak membalas respon tersebut." (Wawancara dengan key informan Krishna Dwi Nugraha, Selasa, 15 Juni 2021 Pukul 07.45 WIB)

Informan kesatu dengan nama Muhammad Ihsan yang mengatakan bahwa komentarnya tidak pernah mendapat feedback dari admin twitter@djplkemenhub151,

"Tidak pernah dapet feedback, selama ini sepertinya emang adminnya kurang aktif balesin komen-komen ya karena yang saya lihat setiap postingan yang ada komennya bahkan bertanya itu tidak pernah ada balesan" (Wawancara dengan informan Muhammad Ihsan, Selasa, 29 Juni 2021, pukul 16.00 WIB).

\section{Gambar 3 Screenshot komentar informan dengan nama Muhammad Ihsan yang tidak mendapatkan feedback dari admin twitter@djplkemenhub151 (Sumber: twitter@djplkemenhub151)}

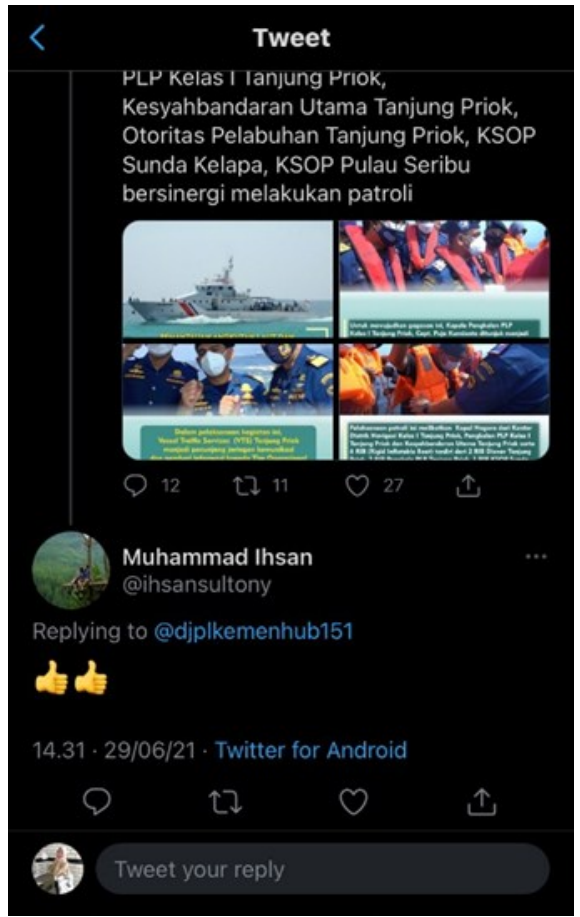

Hal yang sama disampaikan oleh informan kedua dengan nama Mustika Desi Rahmadhan yang mengatakan bahwa komentarnya belum pernah mendapat feedback dari admin twitter@djplkemenhub151,

"Belum pernah dapet feedback, tapi yang saya lihat memang kurang ada interaksi ya, soalnya dikolom komennya itu jarang sekali ada komen. Jadi memang sepertinya cuma untuk sekedar menyampaikan informasi ya, bukan untuk berinteraksi sama khalayaknnya." (Wawancara dengan informan tambahan Mustika Desi Rahmadhan, Selasa, 29 Juni 2021 Pukul 19.05 WIB)

Gambar 4 Screenshot komentar informan dengan nama Mustika Desi Rahmadhan yang tidak mendapatkan feedback dari admin twitter @djplkemenhub151 (Sumber: twitter @djplkemenhub151) 


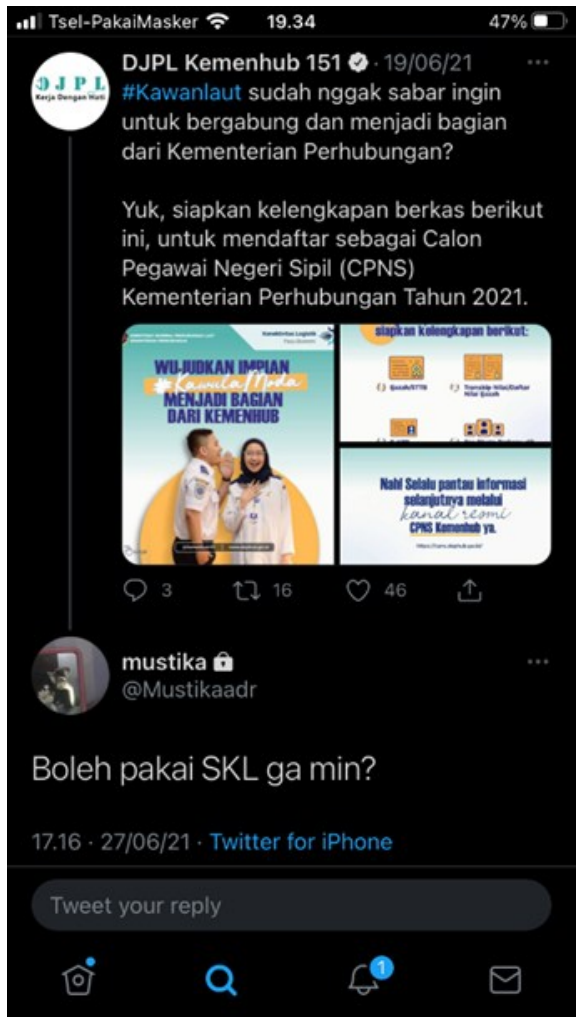

\section{The Circular Model of SoMe (Model Sirkuler Media Sosial)}

Dalam pengelolaan media sosial twitter DJPL perlu adanya interaksi antara follower dan admin agar dapat diketahui keefektifan dari penyebaran informasi yang dilakukan melalui media sosial tersebut. Oleh karena itu, pada penelitian ini menggunakan Teori The Circular Model of SoMe untuk mengetahui pemanfaatan media sosial twitter sebagai media penyebaran informasi publik oleh Humas DJPL sudah optimal atau belum.

a. Share (berbagi)

Pada tahap share, lembaga atau instansi pemerintah dapat mengenali karakteristik audiennya sehingga dapat membuat konten yang sesuai dengan kebutuhan followernya. Dalam tahap ini juga dapat mengetahui siapa yang menerima pesan, keberadaan audiennya, konten apa yang akan dipublikasikan sesuai dengan platform yang telah ditetapkan.

Key informan dengan nama Krishna Dwi Nugraha menjelaskan bahwa proses share atau penyebaran informasi publik pada akun twitter DJPL dimulai dari membuat konsep konten, lalu meminta koreksi atau persetujuan dari Kepala Sub Bagian Humas (Kasubbag Humas) dan Kepala Bagian Organisasi dan Humas (Kabag Bagormas). Jika sudah disetujui, konten tersebut dapat dipublikasikan ke twitter,

"Yang pertama kita membuat konten, konten itu bisa kita buat berdasarkan kegiatan yang dilaksanakan ataupun berbagai kebijakan-kebijakan yang baru. Jika konsep konten tersebut sudah jadi kita meminta koreksi atau persetujuan dari Kasubbag Humas, nanti dari Kasubbag Humas diteruskan ke Kabag Organisasi dan Humas. Jika sudah oke dari Pak Kabag bisa naik langsung ke twitter seperti itu. Jadi tidak sampai ke Sesdit atau Dirjen, tidak semua konten sampai ke pimpinan tertinggi hanya beberapa konten tertentu saja." (Wawancara dengan key informan Khrisna Dwi Nugraha, Selasa, 15 Juni 2021 Pukul 07.45 WIB)

Pada tahap share, pengelolaan media sosial twitter DJPL harus memperhatikan 3 hal antara lain participate, connect, dan build trust. Pada 
poin participate, Humas DJPL memilih media sosial yang tepat untuk publiknya, menentukan tujuan, dan membuat perencanaan kontenkonten. Pada poin connect, Humas DJPL menentukan target khalayak dan menyajikan konten-konten yang menarik dan informatif. Pada poin build trust, Humas DJPL memberikan informasi-informasi yang valid dan memiliki sumber yang jelas,

"Poin participate, kami memilih twitter sebagai media penyebaran informasi publik Kemudian kami menentukan tujuan dari aktivasi twitter yaitu untuk menyebarkan informasi publik dan menciptakan komunikasi dua arah antara instansi DJPL dan publiknya. Setelah mengetahui tujuan secara jelas, kami membuat perencanaan konten-konten yang akan dipublikasikan pada akun twitter@djplkemenhub151 meliputi informasi terkait kebijakan perhubungan laut, kegiatan-kegiatan DJPL seperti patroli keselamatan berlayar, Tol Laut, Proyek Strategis Nasional, Pelabuhan Patimban, pembangunan-pembangunan pelabuhan, kepelautan, perkapalan serta kenavigasian. Pada poin connect, kami menentukan target khalayak yaitu khususnya para pengguna jasa, stakeholder, dan juga masyarakat. Kemudian pada twitter DJPL, kami menyajikan konten-konten yang dikemas menarik agar masyarakat tergerak untuk memberikan like, comment, retweet, saran, dan lain-lain. Pada poin build trust,melaluitwitter@djplkemenhub151 kami menyampaikan informasi publik yang valid dan memiliki sumber yang jelas. Kemudian kami olah informasi tersebut menjadi sebuah konten yang menarik dan ringan sehingga mudah dipahami oleh target khalayak." (Wawancara dengan key informan Krishna Dwi Nugraha, Selasa, 15 Juni 2021 Pukul 07.45 WIB)

Participate: Pemilihan twitter sebagai media penyebaran informasi publik oleh Humas DJPL sudah tepat. Tujuan dilakukannya aktivasi media sosial twitter @djplkemenhub151 adalah sebagai menyebarkan informasi publik dan menciptakan komunikasi dua arah antara instansi Direktorat Jenderal Perhubungan Laut dan publiknya. Humas DJPL tidak hanya menggunakan media sosial twitter, namun terdapat beberapa media sosial yang juga dipergunakan antara lain Facebook, Instagram, Tiktok, dan Youtube. Adapun konten yang disajikan pada akun twitter DJPL adalah informasi mengenai perhubungan laut seperti kebijakan dan kegiatan-kegiatan DJPL seperti patroli keselamatan berlayar, Tol Laut, Proyek Strategis Nasional, Pelabuhan Patimban, pembangunan-pembangunan pelabuhan, kepelautan, perkapalan, serta kenavigasian. Connect: Humas DJPL menentukan target khalayak yang terdiri dari para pengguna jasa, stakeholder, dan masyarakat. Kemudian pada twitter DJPL, kami menyajikan konten-konten yang dikemas menarik agar masyarakat tergerak untuk memberikan like, comment, retweet, atau share. Fitur retweet, like, 
comment, share juga dimanfaatkan untuk membangun komunikasi dua arah kepada target khalayaknya. Build Trust: melalui twitter@djplkemenhub151, Humas DJPL menyampaikan informasi publik yang valid dan memiliki sumber yang jelas. Kemudian Humas DJPL mengolah informasi tersebut menjadi sebuah konten yang menarik dan ringan sehingga mudah dipahami oleh target khalayak. membuat konsep konten, lalu meminta koreksi atau persetujuan dari Kepala Sub Bagian Humas (Kasubbag Humas) dan Kepala Bagian Organisasi dan Humas (Kabag Bagormas). Jika sudah disetujui, konten tersebut dapat dipublikasikan pada twitter @djplkemenhub151. Sehingga semua kontenkonten yang dihasilkan pada twitter DJPL sudah sesuai dengan UU Keterbukaan Informasi Publik.

\section{b. Optimize (Optimisasi)}

DJPL dalam optimize atau mengoptimalkan penggunaan twitter sebagai media penyebaran informasi publik terdapat dua poin yang harus di perhatikan, yaitu listen \& learn, dan take part in authentic conversation. Pada poin listen, Humas DJPL melakukan pengecekan mention dan feedback yang masuk secara manual. Pada poin learn, Humas DJPL memiliki agenda atau jadwal dalam mempublikasikan konten-konten. Pada poin take part in authentic conversation, Humas DJPL belum memiliki strategi khusus karena twitter pengelolaannya masih satu admin dengan media sosial DJPL yang lain seperti Facebook, Instagram, Youtube, dan Tiktok,

"Pada tahap optimize, poin listen, kami melakukan pengecekan mention dan feedback yang masuk dari follower secara manual, biasanya kami menggunakan fitur notifications dan twitter activity. Poin learn, kami sudah memiliki agenda atau jadwal dalam memposting konten-konten yang penyusunannya dilakukan setiap hari jumat untuk publikasi seminggu kedepan sehingga konten-konten dapat dipublikasikan rutin dan sesuai jadwal. Pada poin take part in authentic conversation belum ada strategi khusus karena twitter pengelolaannya masih satu admin dengan media sosial DJPL yang lain seperti facebook, instagram, youtube, dan tiktok. Cara kami mengoptimalkan yaitu dengan menggunakan fungsi hashtag secara rutin dan konsisten seperti \#KawanLaut, \#TransportasiMaju, \#EkonomiBangkit, \#SMRTHublaPastinya, dan \#DJPLKerjaDenganHati untuk meningkatkan terjadinya interaksi antara follower dan admin twitter DJPL. Selain itu, setelah memposting konten kami terkadang share juga via Twitter Fleets agar follower tidak terlewat informasi yang kami berikan." (Wawancara dengan key informan Khrisna Dwi Nugraha, Selasa, 15 Juni 2021 Pukul 07.45 WIB)

Pada tahap ini, proses dibagi menjadi dua poin. Poin pertama adalah listen \& learn. Pada poin listen, Humas DJPL melakukan pengecekan mention dan feedback yang masuk 
dari follower secara manual melalui fitur Tweet Activity yang tersedia pada setiap tweet yang diunggah dan Notifications. Pada poin learn, Humas DJPL telah memiliki agenda atau jadwal dalam memposting konten-konten yang penyusunannya dilakukan setiap hari jumat untuk publikasi seminggu kedepan sehingga konten-konten tersebut dapat dipublikasikan rutin dan sesuai jadwal.

Poin kedua adalah take part in authentic conversations. Dalam tahapan ini, Humas DJPL belum memiliki strategi khusus untuk mengembangkan akun twitternya, termasuk cara untuk melibatkan diri dalam perbincangan di media sosial twitter. Adapun cara lain yang digunakan oleh Humas DJPL dalam mengoptimalkan yaitu dengan menggunakan fungsi hashtag secara rutin dan konsisten seperti \#KawanLaut, \#TransportasiMaju, \#EkonomiBangkit, \#SMRTHublaPastinya, dan \#DJPLKerjaDenganHati untuk meningkatkan terjadinya interaksi antara follower dan admin twitter DJPL. Selain itu, terkadang setelah memposting konten, Humas DJPL juga membagikan postingan konten via Twitter Fleets agar follower tidak terlewat informasi yang kami berikan.

c. Manage (Mengelola)

Key informan dengan nama Khrisna Dwi Nugraha menuturkan bahwa dalam manage atau mengelola media sosial twitter terdapat 3 poin yang perlu diperhatikan. Pertama, bagaimana subjek melakukan media monitoring. Pada poin ini, Humas DJPL melakukan media monitoring secara manual. Kedua, bagaimana subjek memberikan respon yang cepat (quick responses). Pada poin ini, Humas DJPL belum menggunakan tools (alat tertentu) untuk melakukan otomatisasi pembalasan pesan atau komentar dari follower. Ketiga, bagaimana subjek melakukan interaksi dalam waktu yang sebenar-benarnya (real-time interaction). Pada poin ini. Humas DJPL belum pernah melakukan real-time interaction,

"Pada tahap manage, kami melakukan media monitoring yang dilakukan secara manual melalui fitur Notifications dan Tweet Activity. Dalam hal ini, pengelolaan twitter belum dilakukan secara maksimal karena adanya kendala keterbatasan Sumber Daya Manusia (SDM) sehingga twitter dikelola oleh satu admin yang sama dengan media sosial DJPL lainnya. Karena tidak adanya admin pengelola khusus, seringkali media monitoring tidak dilakukan secara rutin pada tiap konten. Pada poin quick responses, kami belum menggunakan tools (alat tertentu) untuk melakukan otomatisasi pembalasan pesan atau komentar dari follower. Jadi, hal tersebut dilakukan secara manual oleh admin. Pada poin real-time interaction, kami belum pernah melakukan interaksi dalam waktu yang sebenar-benarnya (real-time interaction) di media sosial twitter DJPL" (Wawancara dengan key informan 
Khrisna Dwi Nugraha, Selasa, 15 Juni 2021 Pukul 07.45 WIB)

Lebih lanjut key informan dengan nama Krishna Dwi Nugraha menjelaskan bahwa dalam manage atau mengelola twitter sebagai media penyebaran informasi publik, Humas DJPL masih memiliki kendala yaitu keterbatasan Sumber Daya Manusia (SDM) jadi dalam penyebarluasan konten-konten pada seluruh media sosial DJPL hanya dikelola oleh satu admin:

"Ya mungkin kendala saat ini ya seperti itu jadi masih satu admin untuk penyebarluasan konten kita dari youtube, twitter, instagram, dan facebook. Kedepannya kalau bisa karena kan kendala kita juga keterbatasan SDM ya, jadi saat ini masih satu admin untuk menyebarluaskan suatu konten." (Wawancara dengan key informan Khrisna Dwi Nugraha, Selasa, 15 Juni 2021 Pukul 07.45 WIB)

Hasil pertama yang didapatkan dari tahapan manage adalah media monitoring. Humas DJPL melakukan media monitoring dengan cara menyaring isu yang tersebar dan memisahkan antara yang positif, negatif, dan netral. Monitoring ini dilakukan secara manual dan laporannya dibuat setiap bulan. Poin selanjutnya adalah quick reponses. Berdasarkan hasil penelitian yang dilakukan peneliti, Humas DJPL tidak melakukan perannya sebagai sumber informasi, karena banyak komentar yang tidak dibalas. Humas DJPL juga belum menggunakan tools tertentu untuk membantu dalam melakukan otomatisasi pembalasan pesan atau komentar darifollower.

Dalam tahap ini masih terdapat kendala yaitu keterbatasan Sumber Daya Manusia (SDM) sehingga sehingga twitter dikelola oleh satu admin yang sama dengan media sosial DJPL lainnya. Karena tidak adanya admin pengelola khusus, seringkali media monitoring tidak dilakukan secara rutin pada tiap konten. Pada poin quick responses, Humas DJPL belum menggunakan tools (alat tertentu) untuk melakukan otomatisasi pembalasan pesan atau komentar dari follower. Hal tersebut dilakukan secara manual oleh admin.

d. Engage (Melibatkan)

Key informan dengan nama Khrisna Dwi Nugraha menuturkan bahwa pada tahapan engage, poin influencer relations, Humas DJPL belum pernah memanfaatkan influencer pada media sosial twitternya, Poin knowing the audience, Humas DJPL belum memiliki cara untuk menarik minat follower agar dapat terlibat interaksi dengan admin twitter DJPL. Poin reach: untuk meraih audien, Humas DJPL belum melakukan interaksi dengan follower secara maksimal,

"Pada tahap engage, poin influencer relations, kami belum pernah 
menggunakan influencer untuk meningkatkan ketertarikan publik pada akun twitter@djplkemenhub151secara khusus. Karena kami sistemnya ketika menggunakan influencer, hasil atau output dari informasi yang disampaikan oleh influencer kami sebarkan juga pada media sosial DJPL yang lain. Misalnya kami pernah menggunakan influencer Babe Cabita untuk menarik follower instagram kami, nah informasi yang disampaikan oleh Babe Cabita kami sebarkan juga pada media sosial facebook, twitter, dan tiktok. Poin knowing the audience: Humas DJPL belum memiliki cara untuk menarik minat follower agar dapat terlibat interaksi dengan admin twitter DJPL. Saat lini fokus penggunaan twitter untuk memberikan informasi publik secara rutin agar tetap menjaga citra baik dari instansi. Poin reach: untuk meraih audien, kami belum melakukan interaksi dengan follower secara maksimal." (Wawancara dengan key informan Krishna Dwi Nugraha, Selasa, 15 Juni 2021 Pukul 07.45 WIB)

Pada tahap engage, poin influencer relations: Humas DJPL belum pernah menggunakan influencer untuk meningkatkan ketertarikan publik pada akun twitter @djplkemenhub151 secara khusus. Poin knowing the audience, Humas DJPL belum memiliki cara yang efektif untuk menarik minat follower agar dapat terlibat interaksi dengan admin twitter@djplkemenhub151. Humas DJPL hanya fokus untuk memberikan informasi publik secara rutin agar tetap menjaga citra baik dari instansi. Sehingga tidak terlalu memperhatikan audiennya, termasuk respon dan feedback yang diberikan oleh audien. Hal tersebut membuat admin twitter DJPL tidak dapat mengenali audiennya dengan baik dan tidak dapat menjalin hubungan yang dekat dengan followernya.

Pada poin selanjutnya dari tahap engage adalah reach, yaitu bagaimana subjek meraih audiennya. Pada poin ini, Humas DJPL belum mampu meraih audiennya karena admin twitter DJPL tidak aktif dalam membalas komentar pada twitter@djplkemenhub151, baik komentar berupa kritik, saran atau pertanyaan, sehingga DJPL tidak dapat meraih followernya dengan cara tersebut.

\section{KESIMPULAN}

Berdasarkan hasil penelitian dan pembahasan yang telah dilakukan, peneliti menyimpulkan bahwa:

a. Pada tahap share, Humas DJPL memilih media sosial twitter, menentukan tujuan, membuat perencanaan konten-konten yang akan dipublikasikan, menentukan target khalayak, dan menyampaikan informasi yang valid.

a. Pada tahap optimize (optimisasi), Humas DJPL melakukan pengecekan mention dan feedback follower, 
memiliki agenda posting konten, belum memiliki strategi khusus, menggunakan fungsi hashtag dan fitur-fitur yang tersedia pada twitter.

b. Pada tahap manage, Humas DJPL melakukan media monitoring namun masih terdapat kendala keterbatasan Sumber Daya Manusia (SDM) sehingga pengelolaan seluruh akun media sosial milik DJPL hanya dilakukan oleh satu admin, jadi twitter DJPL tidak dikelola oleh admin khusus. Hal tersebut yang membuat admin twitter DJPL kurang aktif melakukan interaksi dengan followernya.

c. Pada tahap engage (melibatkan) Humas DJPL belum memiliki cara khusus untuk menjalin hubungan dengan follower dan belum pernah melibatkan influencer untuk meningkatkan ketertarikan publik pada akun twitter @djplkemenhub151. 


\section{DAFTAR PUSTAKA}

Cahyono, A. S. (2016). 79-148-1-Sm (1). Pengaruh Media Sosial Terhadap Perubahan Sosial Masyarakat Di Indonesia, 9(1), 140-157. http://jurnal-unita.org/index.php/publiciana/article/ view/79

Frank Jefkins. (2002). Public Relations. Erlangga.

Herdiana. (2017). Pengelolaan Website Sebagai Media Informasi Publik Pada Bagian Humas Dan Informasi Pemerintah Kota Pekanbaru. Journal of Chemical Information and Modeling, 53 (9), 1689-1699.

Kapoor A. (2011). Branding and sustainable competitive advantage: building virtual presence: building virtual presence. IGI Global.

Kominfo: Pengguna Internet di Indonesia Capai 175,5 Juta $\mid$ Republika Online. (n.d.). Retrieved May 12, 2021, from https://republika.co.id/berita/qhgibx335/kominfo-pengguna-internet-diindonesia-capai-1755-juta-jiw

Luttrel, R. (2019). Social Media How To Engage, Share and Connect. The Rowman \& Littlefield Publishing Group.

Puspitadewi, I., Erwina, W., \& Kurniasih, N. (2016). Pemanfaatan “Twitter Tmcpo. Jurnal Kajian Informasi Dan Perpustakaan, 4(1), 21.

Puspitaningrum, D. R., \& Laura, P. (2020). Teori Kekayaan Media dalam Penggunaan Media Sosial Twitter Sebagai Media Komunikasi Pejabat Publik: Studi Kasus Gerakan Blokir Akun Twitter Juru Bicara Presiden. 8(2), 227-237.

Sugiyono. (2017). Metode Penelitian Kuantitatif, Kualitatif, Dan R\&D. ALFABETA.

Syaban, I., Mewengkang, N. N., \& Golung, A. (2018). Peranan Penggunaan Website Sebagai Media Informasi Dinas Pariwisata Kabupaten Halmahera Utara. Acta Diurna ..., 7(4), 1-11. https://ejournal.unsrat.ac.id/index.php/actadiurnakomunikasi/article/view/22012

Tomasoa, L., Iriani, A., \& Sembiring, I. (2019). Ekstraksi Knowledge tentang Penyebaran \#Ratnamiliksiapa pada Jejaring Sosial (Twitter) menggunakan Social Network Analysis (SNA). Jurnal Teknologi Informasi Dan Ilmu Komputer, 6(6), 677. https://doi.org/10.25126/ jtiik.2019661710 